\title{
IgG subclass responses to Pseudomonas aeruginosa $a-$ and b-type flagellins in patients with cystic fibrosis: a prospective study
}

\author{
J. LAGACÉ, L. PÉLOQUIN, P. KERMANI and T. C. MONTIE*
}

Department of Microbiology and Immunology, Université de Montréal, CP 6128, Succursale Centre-ville, Montréal, Quebec H3C 3J7, Canada and * Department of Microbiology, University of Tennessee, Knoxville, Tennessee 37996, USA

\begin{abstract}
Summary. Sera from 20 cystic fibrosis patients, whose lungs were colonised by Pseudomonas aeruginosa, were examined in a 3-5-year prospective study for any relationship between IgG subclass antibody levels to $P$. aeruginos $a$ a- and b-type flagellins and pulmonary function ( $\mathrm{FEV}_{1}$ and radiological score). Patients were divided into two groups according to their pulmonary status: group 1 comprised 11 patients with poor pulmonary status; group 2 comprised nine patients with relatively good pulmonary status. High concentrations of IgG1, IgG2 and IgG3 antibodies to flagellins, particularly to the b-type, were found in most patients. IgG4 reactivity was observed in only a few patients. Comparison of the two groups of patients showed that those with poor pulmonary status (group 1) had a significantly higher concentration $(p<0.05)$ of IgG3 for two of the three periods studied and of IgG2 for the last period studied. Moreover, IgG3 and IgG1 reactivities to b-type flagellin and IgG3 to a-type flagellin were also increased significantly $(p<0.05)$ in group 1 patients between the first and the last period studied. These patients also showed a significant $(p<0.05)$ time-dependent increase in IgG3 and IgG1 antibody concentrations. These data demonstrate that cystic fibrosis patients with poorer pulmonary status have higher IgG3 levels to flagellin than other cystic fibrosis patients. High concentrations of strong opsonic IgG3 and, to a lesser degree, of $\mathrm{IgGl}$ antibodies may increase pulmonary inflammation and induce heightened pulmonary deterioration.
\end{abstract}

\section{Introduction}

Pseudomonas aeruginosa is a major cause of nosocomial infections and morbidity and mortality in patients with cystic fibrosis (CF). ${ }^{1,2}$ The pathogenesis of $P$. aeruginosa infection in $\mathrm{CF}$ patients presents several particular features. The infection remains localised in the lung and, despite a heightened immunological response to $P$. aeruginosa antigens, the organism is rarely eradicated from the lungs. No primary immune deficiency appears to be associated with $\mathrm{CF}^{3}$ The immune response includes a high prevalence of IgG antibodies to $P$. aeruginosa which are associated with a poor prognosis. ${ }^{4-6}$

$P$. aeruginosa infections take a highly variable course in individual $\mathrm{CF}$ patients as demonstrated by the broad range of clinical features that occur following many years of colonisation. Such differences may be a function of the way the immune system reacts to bacterial colonisation. In an attempt to identify those immune responses that correlate with preservation or loss of good clinical status, IgG subclass reactions to different $P$. aeruginosa antigens were examined in $C F$ patients. These included reactions to outer-membrane proteins $\mathrm{F}, \mathrm{H}$ and $\mathrm{I},{ }^{7}$ alginate $^{8}$ and mixtures of bacterial antigens. ${ }^{8-10}$

The pathogenesis of $P$. aeruginosa infection involves many products or structures that contribute to adherence, colonisation or invasion during the early phase of the infection. Among them, $P$. aeruginosa flagella were shown to be an invasive virulence factor ${ }^{11}$ and a possible source of a vaccine. ${ }^{12}$ The single polar flagellum exhibited by $P$. aeruginos a contains flagellins as subunits. Flagellins are denoted "a" or " $b$ " on the basis of subunit molecular mass. ${ }^{13}$ The b-type comprises a homogeneous group with a flagellin of $53 \mathrm{kDa}$. The a-type comprises a heterogeneous group with a flagellin of $43-52 \mathrm{kDa}$ and of one-to-three antigen subtypes, and a cross-reactive, dominant antigen designated $\mathrm{a}_{0} \cdot{ }^{14.15}$ Cross-protection in animals was 
demonstrated among the heterogeneous a-types, supporting evidence for the cross-reactivity of antigen $\mathrm{a}_{0}{ }^{12,16}$

The flagellar antigens resolved in the typing scheme of Ansorg ${ }^{15}$ are of clinical relevance as they were detected in $98 \%$ of all motile $P$. aeruginosa strains in a study of 300 clinical isolates. ${ }^{16}$ High titres of antibody to $P$. aeruginosa flagellin " $a$ " and " $b$ " have been detected in CF patients infected intermittently or chronically with $P$. aeruginosa. ${ }^{15.17}$

The aim of this work was to identify IgG subclass responses to $P$. aeruginos a flagellar antigens type a and $\mathrm{b}$ in two groups of CF adolescents and young adults who had been infected for many years by this bacterium, but who varied in their clinical status.

\section{Materials and methods}

\section{Patient selection and serum collection}

Twenty CF patients of both sexes born between 1969 and 1977 were selected. They were followed at the CF Clinic at St Justine's Hospital, Montreal. All had been chronically colonised with $P$. aeruginosa for at least 3 years since 1987 . At the time of blood collection, the patients were scored clinically for the forced expiratory volume $\left(\mathrm{FEV}_{1}\right.$; percentage predicted $)$ based on a perfect score of 100 points (excellent $=86-100$; good $=71-85 ; \quad$ mild $=56-70 ; \quad$ moderate $=41-55$; severe $\leqslant 40$ or below). Chest radiology scores (CRXSc) were determined independently by radiologists following the Brasfield system ${ }^{\mathbf{1 8}}$ (perfect $=25$, good $=20$, midpoint $=15$, feeble $=10)$. None of the patients had acute exacerbation of respiratory symptoms.

Sera were separated at room temperature within $6 \mathrm{~h}$ of blood collection and stored in divided small volumes at $-70^{\circ} \mathrm{C}$. The $\mathrm{CF}$ patients were divided into two groups based on the sum of the FEV $\mathrm{F}_{1}$ and the CRXSc scores for 1987-1992. Group 1 comprised 11 patients (three males and eight females; mean age $13 \cdot 2$ SD $2 \cdot 4$ years in 1987, range 10-18 years) who had poor pulmonary status as demonstrated by a score mean of 61.7 SD 15.6 (range 94 41) in 1987 and a score mean of $59 \cdot 0$ SD $12 \cdot 0$ (range 78-31) in 1990-1992. Group 2 comprised nine patients (two males, seven females; mean age $13.0 \pm 1.8$ years in 1987 ; range $10-17$ years) who had a relatively good clinical status determined by a score mean of 105.7 SD 16.4 (range 131-79) in 1987 and a score mean of $104 \cdot 1$ SD 13.7 (range 123-87) in 1990-1992. Sera from 24 normal adolescents and young adults (mean age 20.3 SD 4.9 years, range 14-27 years) were collected and used to evaluate the normal IgG subclass distribution as determined by the reagents employed in this study.

\section{Isolation and purification of $a$ - and b-type flagellins}

Common laboratory strains of $P$. aeruginosa, PAO1 and PAK, were used for preparation of b- and a-type flagella, respectively. Flagellins were isolated and purified by the method of Montie et al. ${ }^{19}$ with modifications. ${ }^{20}$ Quantitative evaluation of purified flagellin preparation was based on dry weight.

\section{Monoclonal antibodies against human IgG subclasses}

Mouse hybridomas to human IgGl (clone HP6001), IgG2 (clone HP-6014), IgG3 (clone HP-6050) and IgG4 (clone HP-6025) were purchased from the American Type Culture Collection (ATCC). The IgG monoclonal antibodies (MAbs) from these clones are of World Health Organization reference quality and displayed the desired specificity in immunoassays. MAbs were produced in $75-\mathrm{cm}^{2}$ tissue culture flasks in RPMI 1640 medium (Gibco), supplemented with fetal calf serum (Intergen, $\mathrm{Co}$ ) $10 \%$ and gentamicin $50 \mu \mathrm{g} / \mathrm{ml}$. In preliminary studies, each MAb supernate was tested by ELISA against the four human myelomas (IgG1-IgG4; Sigma) to confirm that each was specific for its respective IgG subclass, and did not cross-react with heterologous human myeloma cells in the dilution ranges used. Appropriate dilution factors for each of the four subclass-specific antibodies were determined so as to cover a broad range of reactivities. The reactivity of the mouse MAbs to human IgG subclasses in the sera of the 24 normal adolescents and young adults was tested by ELISA. ${ }^{21}$

\section{ELISA}

Purified a- or b-type flagellins $(0.8 \mu \mathrm{g} / \mathrm{ml}$ in $0.5 \mathrm{M}$ sodium carbonate buffer, $\mathrm{pH} 9.6$ ) were adsorbed overnight at $4^{\circ} \mathrm{C}$ to the wells of polystyrene plates (Nunc, Denmark) (80 ng/well) and processed as described previously $^{7}$ with slight modifications. Briefly, the plates were blocked with PBS containing Tween-20 $0.05 \% \mathrm{v} / \mathrm{v}$ and skimmed milk $1 \% \mathrm{w} / \mathrm{v}$ (PBS-M). In preliminary experiments, serum samples were diluted 1 in 100 and 1 in 1000 . It was found that these gave comparable results and in later experiments, only the 1 in 1000 dilution was used. After incubation of sera for $1 \mathrm{~h}$ at $37^{\circ} \mathrm{C}$, the wells were washed and incubated with MAbs to IgG1, IgG2, IgG3 or IgG4 for $1 \mathrm{~h}$ at $37^{\circ} \mathrm{C}$. Optimal dilutions of MAbs were determined by the preliminary experiments as cited above. The plates were developed with goat anti-mouse IgG conjugated to horseradish peroxidase (Dimension Zymed, San Francisco, CA, USA) for $1 \mathrm{~h}$ at $37^{\circ} \mathrm{C}$. The colour reaction was allowed to develop for $30 \mathrm{~min}$ in the presence of O-phenylenediamine (Sigma) $0.4 \mathrm{mg} / \mathrm{ml}$ and then read in a microplate reader (Dynatech MR 7000 , Fisher Co.). Tests were performed in quadruplicate. Two sera, negative for antibodies to $P$. aeruginos $a$ antigens, were used as controls. To quantify the ELISA reactivity of each IgG subclass of CF serum against purified flagellar antigens, parallel ELISAs were performed as follows. Serial dilutions of human myelomas IgG1-IgG4 at $0.015-2 \mu \mathrm{g} / \mathrm{ml}$ were coated on polystyrene microtitration plates and allowed to react with the same preparation of MAb supernates 
used in the first series of ELISA described above. From standard curves of ELISA value reactivity of $\mathrm{MAb}$ supernates against different concentrations of IgG subclass myeloma, the quantity of equivalent IgG subclass immunoglobulins $(\mu \mathrm{g} / \mathrm{ml})$ was determined by multiplying the values obtained on standard curves by 1000 , the dilution factor of sera.

\section{SDS-PAGE and immunoblotting}

Separating gels (acrylamide 10\%: NN'methylene bis acrylamide $0.27 \%$ ) with a stacking gel (acrylamide $4 \%$ : NN'methylene bis acrylamide $0 \cdot 11 \%$ ) were used for SDS-PAGE as described by Laemmli. ${ }^{22}$ Purified flagellar antigens $(0.5 \mathrm{mg} / \mathrm{ml})$ were suspended in $62.5 \mathrm{~mm}$ Tris- $\mathrm{HCl}$ buffer, $\mathrm{pH} 6.8$, containing SDS $2 \%$ $\mathrm{w} / \mathrm{v}, \beta$-mercaptoethanol $5 \% \mathrm{v} / \mathrm{v}$, glycerol $10 \% \mathrm{v} / \mathrm{v}$ and bromophenol blue $0.001 \% \mathrm{v} / \mathrm{v}$ (BioRad Laboratories, Richmond, CA, USA), were heated (1 min, $95^{\circ} \mathrm{C}$ ) and electrophoresed together with protein mol.-wt standards at $25 \mathrm{~mA} /$ gel at room temperature for $2 \mathrm{~h}$. Subsequently, the gels were either stained with silver $^{23}$ or the proteins were transferred electrophoretically ${ }^{24}$ to polyvinylidene difluoride membranes (PVDF; DuPont) at $330 \mathrm{~mA}$ for $1 \mathrm{~h}$ at room temperature. The membranes containing the separated antigens were cut into strips and were blocked by incubation for $30 \mathrm{~min}$ at $37^{\circ} \mathrm{C}$ in PBS-M. The strips were washed with PBS-Tween 20 (PBS-T) and incubated overnight at $4^{\circ} \mathrm{C}$ with a 1 in 200 dilution of patient serum in PBS-M buffer. They were then washed three times with PBS-T, each time for $5 \mathrm{~min}$, and further incubated with MAbs to IgG1, IgG2, IgG3 or IgG4 for $1 \mathrm{~h}$ at $37^{\circ} \mathrm{C}$. After incubation, the strips were washed again with PBS-T, and then incubated with a 1 in 1000 solution of goat anti-mouse IgG antibody labelled with alkaline phosphatase (Gibco-BRL) in PBS-M buffer for $1 \mathrm{~h}$ at $37^{\circ} \mathrm{C}$. Afterwards, the strips were washed three times with PBS-T, each time for $10 \mathrm{~min}$, and developed with nitroblue tetrazolium chloride and 5-bromo-4-chloro-3-indolylphosphate $p$-toluidine salt in $0.1 \mathrm{~m}$ Tris buffer (Gibco-BRL).

\section{Analysis of data}

Analyses were made of ELISA measurements of IgG subclass responses to the a- and the b-type flagella in sera collected over three periods $(1987,1988-1989$ and 1990-1992). The quantities of equivalent human IgG subclass $(\mu \mathrm{g} / \mathrm{ml})$ that had reacted with flagellar antigens in sera of group 1 and 2 patients were compared statistically by analysis of variance followed by Student's $t$ test. Reactivities between the three periods in each group were also compared statistically.

\section{Results}

The IgG subclass mean values found in the 24 normal control sera (IgG1, 60.3 SD $24 \cdot 7 \%$; IgG2, 32
A

B

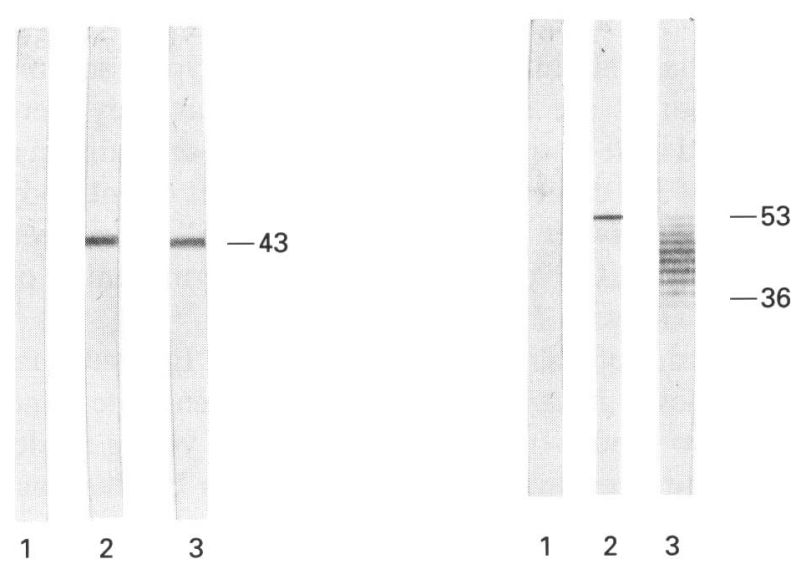

Fig. 1. Immunoblot of purified $P$. aeruginosa flagellins with a negative control serum (lane $\mathbf{1}$ ) and representative sera from $C F$ patients (2 and 3). A: reactions of the 43-kDa a-type flagellin; B: b-type flagellins. The multiple bands in panel $\mathrm{B}$ of $53-36 \mathrm{kDa}$ correspond to commonly observed b-type flagellin degradation products visible only on Western blots.

SD $31 \%$; IgG3, $6.7 \mathrm{SD} 8 \%$; IgG4, 1 SD $2.9 \%$ ) were in conformity with reference value distributions: IgG1, $60 \cdot 3-71 \cdot 5 \%$; IgG $2,19 \cdot 4-31 \%$; IgG3, 5.0-8.4\%; IgG4, $0 \cdot 7-4 \cdot 2 \% .^{25}$

The purified a- and b-type flagellins analysed by SDS-PAGE and stained with silver showed a $53-\mathrm{kDa}$ protein (b-type flagellin) and a protein of $c .43 \mathrm{kDa}$ (atype flagellin) (data not shown). Specific reactivities of patients' sera to $a-$ and b-type flagellins were analysed by immunoblotting. As shown in fig. 1, negative control sera did not react with either flagellar antigen, and sera with a positive reaction in ELISA to a-type flagellin showed reactivity only against the corresponding blotted 43-kDa antigen (fig. 1A). Patients' sera exhibiting a positive reaction against b-type flagellin showed two possible patterns-reactivity either with one band of $53 \mathrm{kDa}$, or additionally with multiple minor bands from $53 \mathrm{kDa}$ to $36 \mathrm{kDa}$ (fig. 2B). These bands co-reacted with a murine MAb to b-type flagellin further verifying the identification of flagellar b-type antigen represented by one band of $53 \mathrm{kDa}$ and other bands of commonly observed flagellin degradation products visible only on immunoblots (data not shown).

By quantitative ELISA, the levels of IgG1, IgG2, IgG3 and IgG4 antibodies to a- and b-type flagellins were assessed in the sera of $20 \mathrm{CF}$ adolescents and young adults who had been colonised with $P$. aeruginosa for long periods. The profiles of subclassspecific flagellin binding were analysed with respect to the patients' clinical characteristics: group 1 comprised 11 patients with poor pulmonary functions and group 2 comprised nine patients with relatively good pulmonary functions. Three sera from each patient collected at different times between 1987 and 1992 were analysed. Sera from two normal individuals of similar ages that were negative for antibodies to $P$. aeruginosa antigens were used as negative controls. 


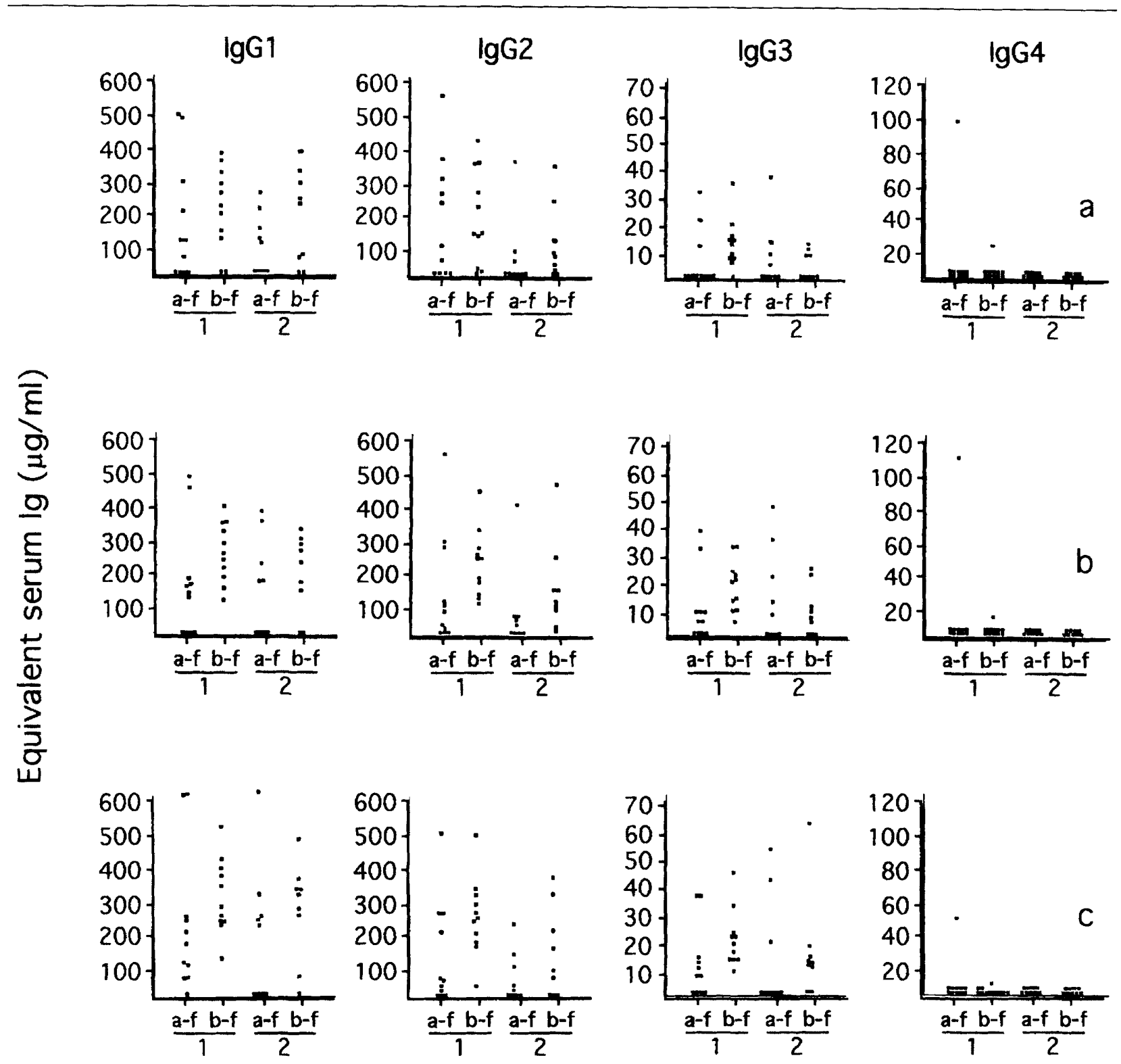

Fig. 2. Comparison of IgG subclass antibody concentrations to a-type flagellin (a-f) and b-type flagellin (b-f) as measured by a quantitative ELISA in $P$. aeruginosa CF patients with poor (group 1) and relatively good (group 2) pulmonary status. a, 1987; b, 1988-89; c, $1990-92$.

Table I. Subclass reactivity of anti-P. aeruginosa a-type flagellin IgG determined by ELISA in relation to clinical status in CF patients

\begin{tabular}{|c|c|c|c|c|c|c|c|c|c|}
\hline \multirow{3}{*}{$\begin{array}{l}\text { Year } \\
\text { of serum } \\
\text { collection }\end{array}$} & \multicolumn{9}{|c|}{ Mean $(\%)^{*}$ of equivalent IgG subclass antibodies $(\mu \mathrm{g} / \mathrm{ml})$} \\
\hline & \multicolumn{3}{|c|}{ IgG1 } & \multicolumn{3}{|c|}{ IgG2 } & \multicolumn{3}{|c|}{ IgG3 } \\
\hline & Group 1 & Group 2 & $\mathrm{p}$ value & Group 1 & Group 2 & $\mathrm{p}$ value & Group 1 & Group 2 & $\mathrm{p}$ value \\
\hline 1987 & $169(49)$ & $99(59)$ & NS & $173(50)$ & $61(36)$ & NS & $6(2) \dagger$ & $8(5)$ & NS \\
\hline $1988-1989$ & $161(52)$ & $145(63)$ & NS & $138(45)$ & $73(31)$ & NS & $11(3)$ & $14(6)$ & NS \\
\hline $1990-1992$ & $232(61)$ & $186(70)$ & NS & $137(36)$ & $66(25)$ & NS & $12(3) \dagger$ & $13(5)$ & NS \\
\hline
\end{tabular}

NS, not significant.

* Relative concentrations (\%) of each IgG subclass immunoglobulin in the total IgG.

$\dagger$ The difference between 1987 and $1990-1992$ values were significant $(\mathrm{p}<0 \cdot 05)$.

Absorbance values for each serum sample were substracted from the absorbance of the control test.

Analysis of the ELISA results revealed that more patients' sera reacted with b-type than with a-type flagellin (fig. 2). Indeed, for 1987 and 1990-1992, IgG1 and $\operatorname{IgG} 2$ responses were positive, respectively, in 60 and $75 \%$, and 50 and $65 \%$ of the patients to a-type flagellin, compared with positive responses of 80 and $95 \%$, and 85 and $100 \%$ to the b-type flagellin.

IgG1 and IgG2 specific antibodies to flagellar antigens showed changing reactivity with time in the two groups of CF patients (tables I and II, fig. 2). 
Table II. Subclass reactivity of anti- $P$. aeruginosa b-type flagellin $\operatorname{lgG}$ determined by ELISA in relation to clinical status in CF patients

\begin{tabular}{|c|c|c|c|c|c|c|c|c|c|}
\hline \multirow{3}{*}{$\begin{array}{c}\text { Year } \\
\text { of serum } \\
\text { collection }\end{array}$} & \multicolumn{9}{|c|}{ Mean $(\%)^{*}$ of equivalent IgG subclass antibodies $(\mu \mathrm{g} / \mathrm{ml})$} \\
\hline & \multicolumn{3}{|c|}{ IgG1 } & \multicolumn{3}{|c|}{$\operatorname{IgG} 2$} & \multicolumn{3}{|c|}{$\operatorname{lgG} 3$} \\
\hline & Group 1 & Group 2 & $\mathrm{p}$ value & Group 1 & Group 2 & $\mathrm{p}$ value & Group 1 & Group 2 & p value \\
\hline 1987 & $214(50) \dagger$ & $181(61)$ & NS & $197(46)$ & $111(37)$ & NS & $14(3) \dagger$ & $5(2)$ & $0 \cdot 01$ \\
\hline $1988-1989$ & $256(50)$ & $191(53)$ & NS & $236(46)$ & $157(44)$ & NS & $19(4)$ & $9(3)$ & 0.05 \\
\hline $1990-1992$ & $319(53) \dagger$ & $272(63)$ & NS & $262(43)$ & $142(33)$ & 0.05 & $22(4) \dagger$ & $17(4)$ & NS \\
\hline
\end{tabular}

NS, not significant.

* Relative concentrations (\%) of each IgG subclass immunoglobulin in the total IgG

$\dagger$ The difference between 1987 and 1990-1992 values were significant $(\mathrm{p}<0.05)$.

Relative concentrations of specific IgG1 to flagellins in group 1, compared with the IgG subclass distribution in normal individuals, were relatively low with a mean of $49 \%$ to a-type and $50 \%$ to b-type for sera collected in 1987; afterwards, the reactivity of group 1 reached a mean of $61 \%$ to a-type and $53 \%$ to b-type for sera collected in 1990-1992 (tables I and II). On the other hand, concentrations of IgG2 antibodies of group 1 against flagellin antigens were relatively elevated with a mean value of $50 \%$ to a-type and $46 \%$ to b-type for sera collected in 1987 ; subsequently, the mean values of $\operatorname{lgG} 2$ dropped to $36 \%$ for a-type and to $43 \%$ for b-type in sera collected in 1990-1992. Proportional values of $\operatorname{IgG} 3$ reactivity of group 1 were near the normal percentage (tables I and II). In group 2, relative concentrations of $\mathrm{IgG} 1, \mathrm{IgG} 2$ and IgG3 to flagellar antigens stayed in the normal distribution in spite of increased values of IgG1 concentration with time. Detection of IgG4 subclass reactivity to flagellar antigens was uncommon. Serum from only one patient from group 1 reacted against type-a flagellum (1987: $96.2 \mu \mathrm{g} / \mathrm{ml} ; 1988-1989: 111 \cdot 2 \mu \mathrm{g} / \mathrm{ml} ; 1990-1992$ : $47.5 \mu \mathrm{g} / \mathrm{ml}$ ) and serum from one other patient of the same group reacted to type-b flagellum (1987: $21.8 \mu \mathrm{g} / \mathrm{ml} ; \quad 1988-1989: 14.3 \mu \mathrm{g} / \mathrm{ml} ; \quad 1990-1992$ : $8 \cdot 7 \mu \mathrm{g} / \mathrm{ml}$ ) (fig. 2).

The IgG subclass reactivities to a-type flagellin for groups 1 and 2 are shown in fig. 2 and table I. Higher levels of IgG1 and IgG2 responses for the three periods studied were observed in group 1 compared with group 2 but the differences were not significant. The IgG3 subclass immunoglobulin $G$ reactivities to a-type flagellin were similar in the two groups.

The IgG subclass reactivities to b-type flagellin in groups 1 and 2 are shown in fig. 2 and table II. The IgG1, IgG2 and IgG3 subclass immunoglobulin $G$ reactivities to b-type flagellin were higher in group 1 . Moreover, the analysis of the paired differences between the two groups showed that IgG2 concentrations for the period 1990-1992 ( $\mathrm{p}<0.05)$, and IgG3 concentrations for the period $1987(p<0.01)$ and 1988-1989 $(\mathrm{p}<0.05)$ were significantly higher in group 1 .

The analysis of IgG subclass reactivities against aand b-type flagellar antigens within each group showed a general and progressive increase with time for IgGl and IgG3 antibody concentrations (fig. 2, tables I and II). However, the increase in reactivity between sera collected in 1987 and 1990-1992 was significant only in sera of group 1 for IgG3 response to a-type flagellin $(\mathrm{p}<0.05)$ (table I) and for IgG1 and IgG3 responses to b-type flagellin $(p<0.05)$ in sera of group 1 collected between 1987 and 1990-1992 (table II). The serum concentration of $\operatorname{IgG} 2$ subclass to a-type flagellin remained relatively constant in the two groups, and also was not significantly increased against b-type flagellin in group 1.

One striking observation was that the two patients with the poorest clinical scores ( $\mathrm{sc}=41$; one of them is now deceased), showed the highest IgG1 responses to a-type flagellin: 495 and $480 \mu \mathrm{g} / \mathrm{ml}$ (1987), 487 and $465 \mu \mathrm{g} / \mathrm{ml}(1988-1989)$, and 615 and $617 \mu \mathrm{g} / \mathrm{ml}$ (1990-1992). At the same time, they showed no $\mathrm{IgG} 2$ reactivity (five of six negative values and one borderline value) against this same type of flagellin. On the other hand, their IgG1 reactivity against b-type flagellin increased from 380 and $352 \mu \mathrm{g} / \mathrm{ml}$ (1987) to 525 and $427 \mu \mathrm{g} / \mathrm{ml}(1990-1992)$ while their IgG2 response to this antigen decreased from 270 and $240 \mu \mathrm{g} / \mathrm{ml}$ (1987) to 180 and $187 \mu \mathrm{g} / \mathrm{ml}(1990-1992)$.

\section{Discussion}

Every CF patient in this study had suffered from chronic recurrent pulmonary infection with $P$. aeruginosa for at least 3 years in 1987. In an attempt to understand why some $\mathrm{CF}$ patients maintained a good clinical status in spite of prolonged $P$. aeruginos $a$ colonisation, IgG subclass reactions to $P$. aeruginosa flagellar antigens in CF patients with good or poor clinical status were examined. Sera from normal adolescents, negative for IgG to $P$. aeruginos $a$ antigens, served as controls.

The data showed that, in both groups, more patients' sera reacted to the b-type than to the a-type flagellin (fig. 2). For the last period studied (1990-1992), IgG1, IgG2 and IgG3 antibodies to the b-type flagellin were detected, respectively, in $95 \%$, $85 \%$ and $90 \%$ of patients compared with $75 \%, 66 \%$ 
and $50 \%$ of patients to the a-type flagellin. The more restricted response to a-type antigen in CF sera may be due to the heterogeneous nature of the a-type flagella. This may reduce the detection of serum reactivity to the common $\mathrm{a}_{0}$ antigen. ${ }^{17}$ It is also very likely that, as seen in a previous study, ${ }^{17}$ some CF patients have harboured organisms with only one flagellin type.

The reason most patients exhibit an increased serum reactivity to flagellar antigens with time is somewhat controversial. It was found that in $\mathrm{CF}$ patients chronically colonised by $P$. aeruginosa, $70 \%$ of the rough isolates lacked flagella. ${ }^{26}$ However, analysis of CF patients' sera suggested that colonisation with flagellate strains had occurred and that at least a certain number of bacteria continued to express flagellar antigens in chronically colonised $\mathrm{CF}$ patients. ${ }^{17}$ It is likely that resurgence of the infection and spreading of $P$. aeruginosa in the lung from time to time may enhance expression of virulence factors such as flagella.

The results of this study show that the IgG3 immune response against b-type flagellin was significantly different $(p<0.05)$ between CF patients with poor (group 1) and good (group 2) pulmonary function for two of the three periods studied (table II). The concentration of IgG2 antibodies to b-type flagellin was also higher in group 1 than group 2. However, the difference between the two groups was only significant $(p<0.05)$ for sera collected in 1990-1992. In the past, significant increases of $\operatorname{IgG} 2$ have been shown to correlate with poor pulmonary status in $\mathrm{CF}$ patients colonised by $P$. aeruginosa. ${ }^{79}$ We also observed that $\operatorname{IgG} 3$ and $\operatorname{IgG1}$ responses to b-type flagellin were increased significantly $(p<0.05)$ as a function of time, in group 1 only. It appears from these data that poor pulmonary function is correlated with a more rapid augmentation of IgG3 and IgGl antibodies to this flagellin type. The finding that an elevated IgG3 response is associated in CF with poor pulmonary function is in general agreement with previous observations regarding antibodies to $P$. aeruginosa antigens. ${ }^{7-10}$

The two CF patients exhibiting the poorest pulmonary status had a disproportionately large reactivity between $\operatorname{IgG} 1$ and $\operatorname{IgG} 2$ to a-type flagellin: $500-600 \mu \mathrm{g} / \mathrm{ml}$ of serum IgG1 and an absence of IgG2 to this protein. A low level of IgG2 may be the result of selective overproduction of $\mathrm{IgGl}$ in response to a particular antigen, similar to that seen in multiple myeloma, where one monoclonal immunoglobulin dominates. However, the significance of this observation is not clear, because the two patients developed IgG2 responses to b-type flagellin.

These data and other work $^{7-10}$ suggest that the nature of the inducing antigen influences IgG isotype expression. It has been suggested previously that IgG2 production is induced predominantly in response to carbohydrate antigens, whereas IgG1 and IgG3 production is generally in response to protein antigens. ${ }^{27}$ However, in various studies ${ }^{27}$ as well as in our results, this general rule is not always followed. ${ }^{7}$ For example, Likavcanova and Lagacé 7 showed that proteins F. H and I of $P$. aeruginosa induced high IgG2 and IgG3 antibody levels in CF patients with poor pulmonary status. Predominant high levels of IgG4 antibodies to protein $\mathrm{H}$ in one group of $\mathrm{CF}$ patients exhibiting a good pulmonary status were also observed. High levels of IgG4 antibodies to different $P$. aeruginosa antigens, including exotoxin $\mathrm{A}$ and alginate (polysaccharide), have also been observed. ${ }^{28}$ In the present study, high IgG4 responses to $P$. aeruginosa flagellar proteins may be considered as an epiphenomenon because these responses were seen in only two patients of group 1 against one type of flagellin. Finally, the fact that two patients reacted very differently to a- and b-type flagellins (two similar proteins) as mentioned above (a very strong $\mathrm{IgG} 1$ response and absence of $\mathrm{IgG} 2$ response to a-type flagellin concomitant with a high IgG1 and $\operatorname{IgG} 2$ response to b-type flagellin) indicates our limited understanding of IgG subclass roles at present.

All these observations concerning the variability of isotype expression suggest that isotype control may be more complex than expected. In the same way, the nature of the subclass response may have important implications concerning the role of serum antibodies in the disease process. The reason that poor pulmonary function is specifically associated with IgG3 antibody concentration and with high increase of IgG1 with time may lie in the biological properties of the $\mathrm{Fc}$ portion of $\operatorname{IgG} 3$ and $\operatorname{IgG} 1$. The abilities of $\operatorname{IgG} 3$, and to a smaller extent IgG1, to activate the classical complement pathway, and to bind to FcR of monocytes and neutrophils, are many times greater than those of IgG2 and IgG4. ${ }^{25,29}$ In CF lung, high IgG1 and IgG3 concentrations may increase complement activation. Such activation induces production of anaphylatoxins (C3a, C4a and C5a) that would increase chemotaxis of neutrophils contributing to pulmonary inflammation, complement-mediated tissue damage and worsened lung condition. The inability of neutrophils to clear infection in CF patients probably does not result from an opsonic defect in the immune response of colonised patients affecting neutrophil function ${ }^{10}$ but may be due to neutrophil elastase that can cleave the $\mathrm{Fc}$ portion of IgG or C3bi on opsonised $P$. aeruginosa as well as CR 1 on neutrophils. ${ }^{30.31}$ Physical factors such as thick mucus secretion in CF lungs and the protective biofilm environment of $P$. aeruginosa microcolonies ${ }^{32}$ may contribute to resistance, leading to a chronically overstimulated immune response. Thus, one approach to the control of $P$. aeruginosa infections in CF patients is to determine which antigens are most useful in provoking an antibody response of appropriate subclass in order to render a high degree of protection against infections caused by this organism, and to provide a safe and effective means of delivering a potent vaccine.

We thank Dr A. Lamarre, Director of the Cystic Fibrosis clinic of the St Justine Hospital (Montreal, Canada) for providing samples 
and making the clinical evaluation of patients, and $\mathrm{Mr} \mathrm{M}$. Bouchard for technical assistance. This work was supported by the Fonds de

\section{References}

1. Bodey GP, Bolivar R, Fainstein V, Jadeja L. Infections caused by Pseudomonas aeruginosa. Rev Infect Dis 1983; 5: 279-313.

2. Gilligan PH. Microbiology of airway disease in patients with cystic fibrosis. Clin Microbiol Rev 1991; 4: 35-51.

3. Schiøtz PO. Systemic and mucosal immunity and non-specific defense mechanisms in cystic fibrosis patients. Acta Pediatr Scand 1982; 301 (Suppl): 55-62.

4. Høiby N. Pseudomonas aeruginosa infection in cystic fibrosis. Diagnostic and prognostic significance of Pseudomonas aeruginosa precipitins determined by means of crossed immunoelectrophoresis. A survey. Acta Pathol Microbiol Scand (Suppl) 1977; 262: 1-96.

5. Döring G, Høiby N. Longitudinal study of immune response to Pseudomonas aeruginosa antigens in cystic fibrosis. Infect Immun 1983; 42: 197-201.

6. Lagacé J, Mercier J, Fréchette $\mathbf{M}$ et al. Circulating immune complexes, antibodies to Pseudomonas aeruginosa, and pulmonary status in cystic fibrosis. $J$ Clin Lab Immunol 1989; 30: 7-11.

7. Likavcanova E, Lagacé J. Quantitative analysis of immunoglobulin G subclass responses to Pseudomonas aeruginosa antigens in cystic fibrosis. $J$ Med Microbiol $1992 ; 36$ : 437-444.

8. Hodson ME, Morris L, Batten JC. Serum immunoglobulins and immunoglobulin $\mathrm{G}$ subclasses in cystic fibrosis related to the clinical state of the patient. Eur Respir $J 1988 ; 1$ : 701-705.

9. Pressler T, Pedersen SS, Espersen F, Høiby N, Koch C. IgG subclass antibody responses to alginate from $P$ seudomonas aeruginosa in patients with cystic fibrosis and chronic $P$. aeruginosa infection. Pediatr Pulmonol 1992; 14: 44-51.

10. Cowan RG, Winnie GB. Anti-Pseudomonas aeruginosa IgG subclass titers in patients with cystic fibrosis: correlations with pulmonary function, neutrophil chemotaxis, and phagocytosis. J Clin Immunol 1993; 13: 359--370.

11. Drake D, Montie TC. Flagella, motility, and invasive virulence of Pseudomonas aeruginosa. J Gen Microbiol 1988; 134: 43-52.

12. Drake D, Montie TC. Protection against Pseudomonas aeruginosa infection by passive transfer of anti-flagellar serum. Can J Microbiol 1987; 33: 755-763.

13. Allison JS, Dawson M, Drake D, Montie TC. Electrophoretic separation and molecular weight characterization of Pseudomonas aeruginosa $\mathrm{H}$-antigen flagellins. Infect Immun 1985; 49: 770-774.

14. Montie TC, Anderson TR. Enzyme-linked immunosorbent assay for detection of $P$ seudomonas aeruginosa $\mathrm{H}$ (flagellar) antigen. Eur J Clin Microbiol Infect Dis 1988; 7: 256-260.

15. Ansorg R. Flagellaspezifisches H-Antigenschema von Pseudomonas aeruginosa. Zentralbl Bakteriol Orig A 1978; 242: 228-238

16. Crowe BA, Enzersberger O, Schober-Bendixen S et al. The first la recherche en santé du Québec (FRSQ) and the Canadian Foundation of cystic fibrosis.

clinical trial of immuno's experimental Pseudomonas aeruginosa flagellar vaccines. Antibiot Chemother 1991; 44: 143-56.

17. Anderson TR, Montie TC, Murphy MD, McCarthy VP. Pseudomonas aeruginosa flagellar antibodies in patients with cystic fibrosis. J Clin Microbiol 1989; 27: 2789-2793.

18. Brasfield D, Hicks G, Soong S-J, Peters J, Tiller R. Evaluation of scoring system of the chest radiograph in cystic fibrosis: a collaborative study. AJR 1980; 134: 1195-1198.

19. Montie TC, Craven RC, Holder IA. Flagellar preparations from Pseudomonas aeruginosa: isolation and characterization. Infect Immun 1982; 35: 281-288.

20. Kelly-Wintenberg K, Anderson T, Montie TC. Phosphorylated tyrosine in the flagellum filament protein of Pseudomonas aeruginosa. J Bacteriol 1990; 172: 5135-5139.

21. Nutman TB, Withers AS, Ottesen EA. In vitro parasite antigeninduced antibody responses in human helminth infections. $J$ Immunol 1985; 135: 2794-2799.

22. Laemmli UK. Cleavage of structural proteins during the assembly of the head of bacteriophage T4. Nature 1970: 227: $680-685$.

23. Morrissey JH. Silver stain for proteins in polyacrylamide gels: a modified procedure with enhanced uniform sensitivity. Anal Biochem 1981; 117: 307-310.

24. Towbin H, Gordon J. Immunoblotting and dot immunobinding-current status and outlook. $J$ Immunol Methods 1984; 72 : $313-340$.

25. Hamilton RG. Human IgG subclass measurements in the clinical laboratory. Clin Chem 1987; 33: 1707-1725.

26. Luzar MA, Thomassen MJ, Montie TC. Flagella and motility alterations in Pseudomonas aeruginosa strains from patients with cystic fibrosis: relationship to patient clinical condition. Infect Immun 1985; 50: 577-582.

27. Hammarström L, Smith CIE. IgG subclasses in bacterial infections. Monogr Allergy 1986; 19: 122-123.

28. Albus A, Saalmann M, Tesch H, Pedersen SS, Döring G. Increased levels of IgG subclasses specific for Pseudomonas aeruginosa exoenzyme and polysaccharide antigens in chronically infected patients with cystic fibrosis. APMIS 1989; 97: 1146-1148.

29. Augener W, Grey HM, Cooper NR, Müller-Eberhard HJ. The reaction of monomeric and aggregated immunoglobulins with $\mathrm{Cl}$. Immunochemistry 1971; 8: 1011-1020.

30. Fick RB, Naegel GP, Squier SU, Wood RE, Gee JBL, Reynolds HY. Proteins of the cystic fibrosis respiratory tract. Fragmented immunoglobulin $\mathrm{G}$ opsonic antibody causing defective opsonophagocytosis. J Clin Invest 1984; 74 : 236-248.

31. Tosi MF, Zakem H, Berger M. Neutrophil elastase cleaves C3bi on opsonized Pseudomonas as well as CR1 on neutrophils to create a functionally important opsonin receptor mismatch. J Clin Invest 1990; 86: 300-308

32. Lam J, Chan R, Lam K, Costerton JW. Production of mucoid microcolonies by Pseudomonas aeruginosa within infected lungs in cystic fibrosis. Infect Immun 1980; 28: 546-556. 